\title{
PROPUESTA DE UN INDICE DE SEQUIA PARA VALUAR LA POSIBLE EXPANSION DE LA CELDA DE HADLEY Y SU RELACIÓN CON LA CRISIS HÍDRICA DE LAS REGIONES SUBTROPICALES DEL HEMISFERIO SUR
}

\section{PROPOSAL FOR AN INDEX OF DROUGHT FOR VALUING THE POSSIBLE EXPANSION HADLEY CELL AND ITS RELATIONSHIP WITH WATER CRISIS SUBTROPICAL REGIONS SOUTHERN HEMISPHERE}

\author{
Poblete, Arnobio Germán ${ }^{1}$; Minetti, Juan Leonidas ${ }^{2}$ \\ ${ }_{1}^{1}$ Profesor y Director del Instituto de Geografía Aplicada(IGA).UNSJ-San Juan -agpoblete@gmail.com \\ ${ }^{2}$ Departamento de Geografía UNT-Tucumán-CONICET y Laboratorio Climatológico Sudamericano - \\ minettil@arnet.com
}

\section{RESUMEN}

La celda de Hadley $(\mathrm{HC})$ es la más importante de la circulación general atmosférica por su rol fundamental en el sistema climático, y por ende su impacto sobre el clima global. Sus principales componentes son: La Convergencia Intertropical de la circulación en superficie -alisios- (ITCZ) con el consiguiente ascenso, condensación y posible precipitación; y la circulación de altura formada por los Contralisios subsidentes (CAS) en las regiones subtropicales de ambos hemisferios, provocando calentamiento y secamiento del aire descendente, con el consiguiente aumento de masa.

Recientemente se ha puesto especial énfasis en los cambios latitudinales de la ITCZ y CAS posiblemente como resultado de un proceso de expansión de la $\mathrm{HC}$ producido por el calentamiento global (CG). Esta intensificación/debilitamiento de la $\mathrm{HC}$ a su vez está asociada/o con el crecimiento/disminución de las precipitaciones en la ITCZ y disminución/crecimiento de las precipitaciones en la banda subtropical, contribuyendo al incremento de las frecuencias de sequías en latitudes medias de ambos hemisferios. En ese marco, se buscó una explicación sobre la intensificación y desplazamiento hacia altas latitudes de la posición del anticiclón subtropical del Pacífico Sur (LSAP).

Para comprobar el impacto descripto del CG sobre la celda de Hadley y de esta en la subsidencia sobre los anticiclones subtropicales del Hemisferio Sur (HS), se construye un índice de sequía hemisférico, con el objeto de relacionarlo con las principales variables asociadas a los procesos precipitantes en el mismo, y de esa manera contextualizar la crisis hídrica que están soportando dichas regiones.

\section{Palabras claves \\ Celda de Hadley; Índice de sequía; Calentamiento Global; Procesos Precipitantes}

\begin{abstract}
Hadley cell $(\mathrm{HC})$ is the most important of the general atmospheric circulation for its fundamental role in the climate system, and therefore its impact on the global climate. Its main components are: Intertropical Convergence circulation in -alisios- surface (ITCZ) with a consequent rise, condensation and precipitation possible; and circulation of height formed by subsiding Contralisios (CAS) in the subtropics of both hemispheres, causing warming and drying the descending air, thereby increasing mass.
\end{abstract}

Recently it has put special emphasis on the latitudinal shifts of the ITCZ and CAS possibly as a result of an expansion of the HC produced by global warming (CG). This intensification / weakening of the

Publicado en formato digital: Dr. Arnobio Germán Pobrete y Dr. Juan Leonidas Minetti. PROPUESTA DE UN INDICE DE SEQUIA PARA VALUAR LA POSIBLE EXPANSION DE LA CELDA DE HADLEY Y SU RELACIÓN CON LA CRISIS HÍDRICA DE LAS REGIONES SUBTROPICALES DEL HEMISFERIO SUR. Revista Geográfica Digital. IGUNNE. Facultad de Humanidades. UNNE. Año 12. No 24. Julio - Diciembre 2015. ISSN 1668-5180 Resistencia, Chaco. 
$\mathrm{HC}$ in turn is associated / or growth / decline in precipitation in the ITCZ and decrease / increase in rainfall in subtropical band, contributing to the increased frequency of droughts in the midlatitudes of both hemispheres. In this context, an explanation on intensifying and high latitudes shift the position of the subtropical anticyclone of the South Pacific (LSAP) was sought.

To check the described impact of CG on the Hadley cell and this subsidence in the subtropical anticyclones over the Southern Hemisphere (SH), hemispheric drought index is constructed, in order to relate the main variables associated with the process precipitating therein, and thus contextualize the water crisis they are enduring these regions.

\section{INTRODUCCIÓN}

La celda más importante de la circulación general atmosférica, es la de Hadley (HC) - ver figura 3-, que abarca aproximadamente el $60 \%$ de la superficie terrestre siendo de fundamental importancia en el sistema climático, y por ende su impacto sobre el clima global (Díaz et al Bradley, 2004). Los principales componentes de esta circulación son: a) La Convergencia Intertropical de la circulación en superficie -alisios-, hacia la zona de convergencia intertropical(ITCZ), con el consiguiente ascenso, condensación y posible precipitación b) La circulación de altura integrada por los Contralisios subsidentes (CAS) en las regiones subtropicales de ambos hemisferios, provocando aumento de masa, calentamiento y secamiento del aire descendente.

Recientemente los investigadores han puesto especial énfasis en los cambios latitudinales de la ITCZ y el CAS resultantes de un proceso de expansión de la HCque sería debido al calentamiento global (Broccoli et al., 2006; Haug et al., 1991; Xiao-Wei Quan et al., 2004; Minetti et al. 2009).La intensificación/debilitamiento de la $\mathrm{HC}$ a su vez está asociada/o con el crecimiento/disminución de las precipitaciones en la ITCZ y disminución/crecimiento de las precipitaciones en la banda subtropical. Esto último podría contribuir al incremento de las frecuencias de sequías en latitudes medias de ambos hemisferios (Hu y Fu, 2007). Varios autores, usando datos de radiación emergente de onda larga (OLR), (Chen, 2002) sugieren que la HC se intensificó desde la década de 1990. Por otra parte Quan et al. (2002), Hu et al. (2005), Mitas y Clement (2005) y Xiao-Wei Quan et al. (2004), mostraron que la $\mathrm{HC}$ se ha extendido en las décadas recientes, resaltando como controversial el hecho que gran parte de los modelos climáticos señalan el efecto contrario al descripto, cuando el sistema climático está sometido a un Calentamiento Global (CG) (Lu at al., 1958), (Kistler et. al., 2007). Se advirtió también que una explicación sobre la expansión o desplazamiento hacia altas latitudes de la posición del anticiclón subtropical del Pacífico Sur (LSAP) frente al CG es restrictivo para la segunda mitad del siglo $X X$, ya que a principios de éste, cuando el calentamiento no fue tan acentuado, él se desplazaba hacia latitudes bajas (Minetti et al., 2009), (Poblete, A.G., 2014), por lo que se advierte que sería inadecuado el uso de series cortas para evaluar al Cambio Climático (CC), debido a la ocurrencia de estos cambios de larga escala, con perturbaciones iguales o superiores a 100 años. En particular esto es válido para aquellos estudios realizados con series de datos del Reanalysis I, que parten desde el año 1948. En las últimas décadas se ha observado un paulatino retorno de las precipitaciones hacia condiciones más secas en el subtrópico Sudamericano (Minetti et al., 2010), (Poblete, A.G., 2014) que parecen extenderse sobre todo el HS (Ummenhofer et al., 2009); Tyson, 1978, Poblete, 2013), utilizando largas series pluviométricas de losCAS de la región árida-semiárida del mismo, como por ejemplo en: Andes Áridos, Sudáfrica y SW de Australia, (Poblete et. al., 2015).

Para verificar el impacto del CG en el incremento de la subsidencia sobre los anticiclones subtropicales del Hemisferio Sur (HS),e indirectamente el comportamiento de la celda de Hadley y su relación con la crisis hídrica que están soportando las regiones citadas,se construye un índice de sequía hemisférico que se describe en datos y métodos; y que los autores demostraron que está asociado con la HC(Poblete, A. G., 2015) con el objeto de relacionarlo con las principales variables asociadas a los procesos precipitantes y de esa manera valuar objetivamente dicho impacto.

Publicado en formato digital: Dr. Arnobio Germán Pobrete y Dr. Juan Leonidas Minetti. PROPUESTA DE UN INDICE DE SEQUIA PARA VALUAR LA POSIBLE EXPANSION DE LA CELDA DE HADLEY Y SU RELACIÓN CON LA CRISIS HÍDRICA DE LAS REGIONES SUBTROPICALES DEL HEMISFERIO SUR. Revista Geográfica Digital. IGUNNE. Facultad de Humanidades. UNNE. Año 12. № 24. Julio - Diciembre 2015. ISSN 1668-5180 Resistencia, Chaco. 


\section{DATOS Y MÉTODOS}

Para realizar esta investigación se emplearon los datos pluviométricos mensuales de una red de estaciones meteorológicas ubicadas en losCAS y latitudes medias del HS, afectadas principalmente por el desarrollo de los anticiclones semipermanentes (ver figuras 1 y 2), que provienen principalmente de Chile Central (CH), Australia (AU) y Sudáfrica (SA), con cinco localidades en cada región, todas ellas proporcionadas por los servicios meteorológicos respectivosdes de el año 1909 hasta 2012, (ver figura 4 y tabla 1 ).

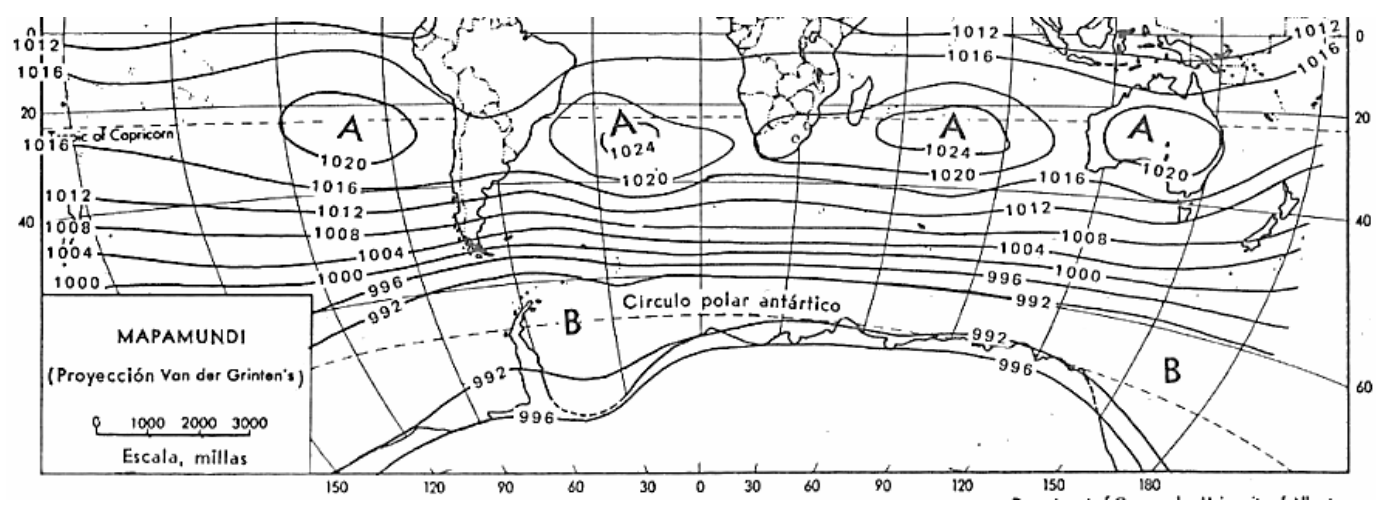

Figura 1: Ubicación media de los anticiclones subtropicales del hemisferio sur en el mes de julio.

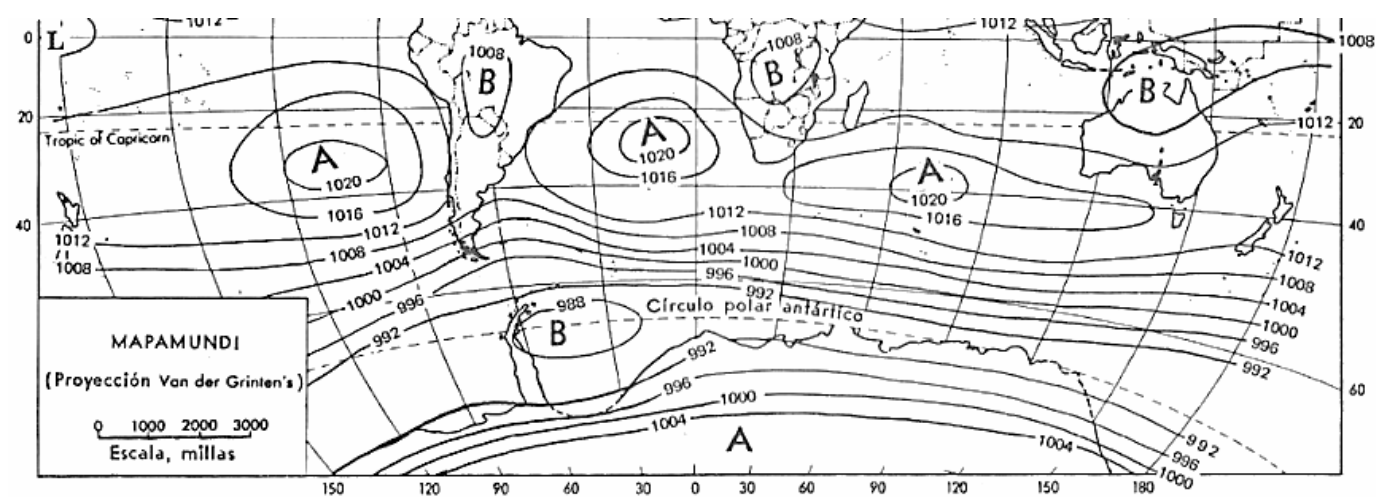

Figura 2: Ubicación media de los anticiclones subtropicales del hemisferio sur en el mes de enero.

Publicado en formato digital: Dr. Arnobio Germán Pobrete y Dr. Juan Leonidas Minetti. PROPUESTA DE UN INDICE DE SEQUIA PARA VALUAR LA POSIBLE EXPANSION DE LA CELDA DE HADLEY Y SU RELACIÓN CON LA CRISIS HÍDRICA DE LAS REGIONES SUBTROPICALES DEL HEMISFERIO SUR. Revista Geográfica Digital. IGUNNE. Facultad de Humanidades. UNNE. Año 12. № 24. Julio - Diciembre 2015. ISSN 1668-5180 Resistencia, Chaco.

En: http://hum.unne.edu.ar/revistas/geoweb/default.htm 


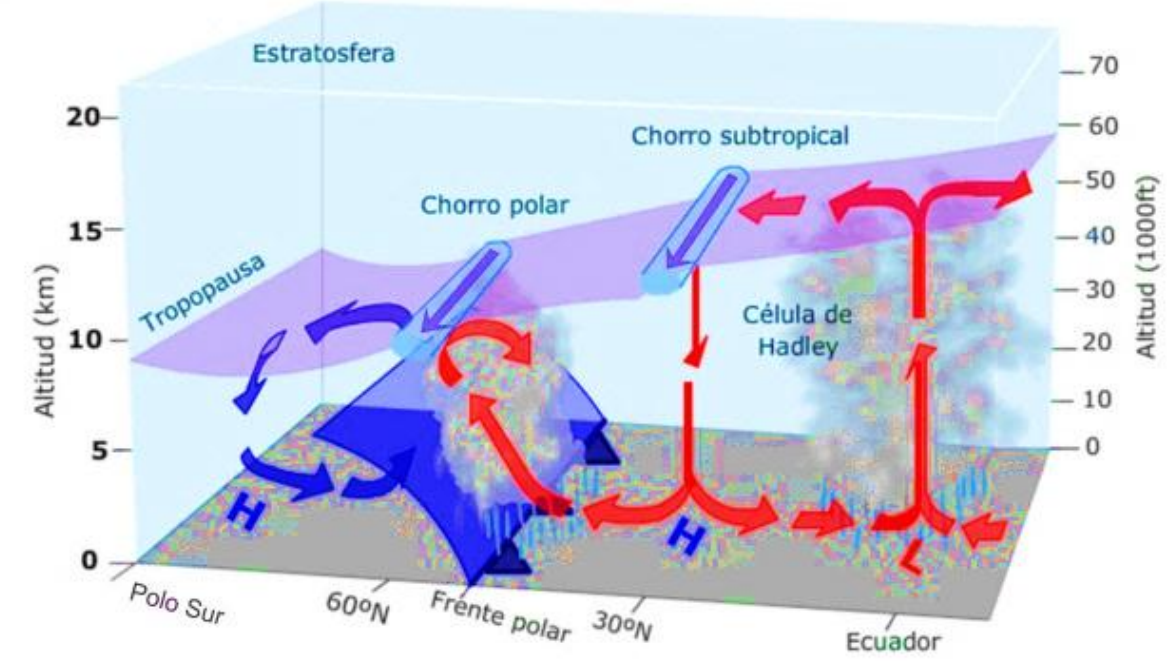

Figura 3: Esquema simplificado de la celda de Hadley en el contexto de la circulación hemisférica.

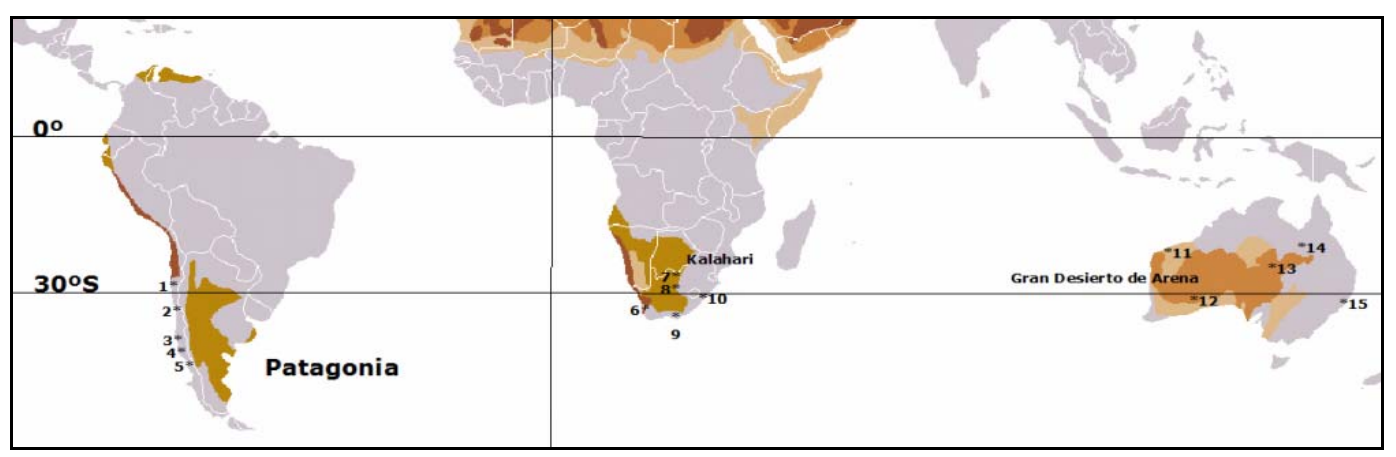

Figura 4: Ubicación de las estaciones meteorológicas utilizadas para la estimación de los ISA regionales o totales (el número asociado al nombre de la localidad se muestra en la tabla 1).

Publicado en formato digital: Dr. Arnobio Germán Pobrete y Dr. Juan Leonidas Minetti. PROPUESTA DE UN INDICE DE SEQUIA PARA VALUAR LA POSIBLE EXPANSION DE LA CELDA DE HADLEY Y SU RELACIÓN CON LA CRISIS HÍDRICA DE LAS REGIONES SUBTROPICALES DEL HEMISFERIO SUR. Revista Geográfica Digital. IGUNNE. Facultad de Humanidades. UNNE. Año 12. No 24. Julio - Diciembre 2015. ISSN 1668-5180 Resistencia, Chaco.

En: http://hum.unne.edu.ar/revistas/geoweb/default.htm 
Revista Geográfica Digital. IGUNNE. Facultad de Humanidades. UNNE. Año 12. № 24. Julio - Diciembre 2015. ISSN 1668-5180 Resistencia, Chaco

\begin{tabular}{|c|c|c|c|c|}
\hline $\mathbf{N}^{\circ}$ orden & Localidad & Lat. & Lon. & Elev. \\
\hline Sud América & & & & \\
\hline $\mathbf{1}$ & La Serena & $29.9 \mathrm{~S}$ & $71.2 \mathrm{~W}$ & $32 \mathrm{~m}$ \\
\hline $\mathbf{2}$ & Santiago Chile & $33.4 \mathrm{~S}$ & $70.7 \mathrm{~W}$ & $520 \mathrm{~m}$ \\
\hline $\mathbf{3}$ & Concepción & $39.5 \mathrm{~S}$ & $73.0 \mathrm{~W}$ & $15 \mathrm{~m}$ \\
\hline $\mathbf{4}$ & Valdivia & $39.7 \mathrm{~S}$ & $73.2 \mathrm{~W}$ & $5 \mathrm{~m}$ \\
\hline $\mathbf{5}$ & Pto. Montt & $41.2 \mathrm{~S}$ & $72.6 \mathrm{~W}$ & $110 \mathrm{~m}$ \\
\hline África & & & & \\
\hline $\mathbf{6}$ & Cape Town & $34.0 \mathrm{~S}$ & $18.2 \mathrm{E}$ & $56 \mathrm{~m}$ \\
\hline $\mathbf{7}$ & Johannesburg & $26.2 \mathrm{~S}$ & $28.1 \mathrm{E}$ & $1676 \mathrm{~m}$ \\
\hline $\mathbf{8}$ & Kimberley & $28.8 \mathrm{~S}$ & $24.7 \mathrm{E}$ & $1196 \mathrm{~m}$ \\
\hline $\mathbf{9}$ & Pto. Elizabeth & $33.9 \mathrm{~S}$ & $25.6 \mathrm{E}$ & $58 \mathrm{~m}$ \\
\hline $\mathbf{1 0}$ & Durban & $29.8 \mathrm{~S}$ & $31.0 \mathrm{E}$ & $12 \mathrm{~m}$ \\
\hline Australia & & & & \\
\hline $\mathbf{1 1}$ & Onslow & $21.1 \mathrm{~S}$ & $115.9 \mathrm{E}$ & $11 \mathrm{~m}$ \\
\hline $\mathbf{1 2}$ & Kalgoorlie & $30.9 \mathrm{~S}$ & $121.1 \mathrm{E}$ & $427 \mathrm{~m}$ \\
\hline $\mathbf{1 3}$ & Alice Spring & $24.5 \mathrm{~S}$ & $133.2 \mathrm{E}$ & $432 \mathrm{~m}$ \\
\hline $\mathbf{1 4}$ & Cloncurry & $20.7 \mathrm{~S}$ & $140.5 \mathrm{E}$ & $200 \mathrm{~m}$ \\
\hline $\mathbf{1 5}$ & Sydney & $33.8 \mathrm{~S}$ & $151.2 \mathrm{E}$ & $39 \mathrm{~m}$ \\
\hline
\end{tabular}

Tabla 1: Estaciones meteorológicas utilizadas para la estimación de los ISA regionales o totales. Su ubicación se muestra en la figura 4.

La metodología básica empleada para el estudio de la relación entre las series fue el análisis de correlación, que consistió en calcular el coeficiente producto-momento de Pearson, (Draper and Smith 1998)cuyo algoritmo es:

$$
r=\frac{1}{n-1} \sum_{i=1}^{n} \frac{\left(x_{i}-\bar{x}\right)}{s_{x}} \frac{\left(y_{i}-\bar{y}\right)}{s_{y}},
$$

Donde $\mathrm{n}=$ número de datos, $\mathrm{x}_{\mathrm{i}}$ es el dato en la posición $\mathrm{i}, \operatorname{con} \bar{x}, \bar{y}$ medias de las dos series, $\mathrm{S}_{\mathrm{x}}, \mathrm{S}_{\mathrm{y}}$ desviaciones estándar de las variables $\mathrm{x}$ e $\mathrm{y}$.

Y para el análisis espacial el Reanalysis I del NCEP y NCAR de la NOAA de los EE.UU.

\section{Test de break regression (BR).}

El procedimiento de las regresiones de ruptura (Break Regression -BR-) consiste en calcularlas punto a punto durante un corrimiento sobre toda la serie temporal, y en cada uno de ellos aplicar un test de significación de la tendencia. Cuando ésta es significativa en un punto dado se lo considera como un cambio abrupto de la recta de regresión, (Mudelsee, M., 2009).

El modelo de regresión de ruptura se escribe para un tiempo continuo como:

Publicado en formato digital: Dr. Arnobio Germán Pobrete y Dr. Juan Leonidas Minetti. PROPUESTA DE UN INDICE DE SEQUIA PARA VALUAR LA POSIBLE EXPANSION DE LA CELDA DE HADLEY Y SU RELACIÓN CON LA CRISIS HÍDRICA DE LAS REGIONES SUBTROPICALES DEL HEMISFERIO SUR. Revista Geográfica Digital. IGUNNE. Facultad de Humanidades. UNNE. Año 12. № 24. Julio - Diciembre 2015. ISSN 1668-5180 Resistencia, Chaco.

En: http://hum.unne.edu.ar/revistas/geoweb/default.htm 


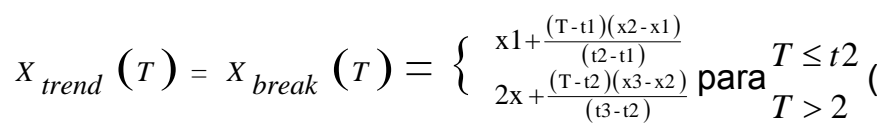

Donde $\mathrm{X}_{\text {break }}(T)$ poblacional es el punto de ruptura poblacional de la tendencia $\mathrm{X}_{\text {trend }}(\mathrm{T})$.

Como se ve (2) tiene cuatro parámetros libres: $x 1, t 2, x 2 y \times 3$. Donde $x i$ son realizaciones de las serie en los tiempos ti, con $\mathrm{i}=1,2,3$.

Una formulación alternativa incluiría los siguientes parámetros: $t 2, x 2, \beta 1=(x 2-x 1) /(t 2-t 1) y \beta 2=(x 3-$ $\mathrm{x} 2$ ) / ( $\mathrm{t} 3$ - $\mathrm{t} 2$ ). Con $\beta \mathrm{i}$ la pendiente de la recta $\mathrm{i}$.

La ruptura (break) describe un cambio en la tendencia lineal en un punto ( $\mathrm{t} 2, \mathrm{x} 2$ ), a partir de las pendientes $\beta 1 \mathrm{a} \beta 2$ correspondientes a las rectas anteriores y posteriores al quiebre. Asumiendo que la desviación estándar $\mathrm{S}$ (i) mide la variabilidad, el modelo de quiebre se ajusta mediante la minimización de la siguiente suma de mínimos cuadrados ponderada:

$\operatorname{SSQW}(x 1, t 2, x 2, x 3)=\sum_{i=1}^{n} \frac{\left[x(i)-x_{\text {break }}(1)\right]^{2}}{S(i)^{2}}$

Dondex $_{\text {break }}(\mathrm{i})$ es la versión muestra en tiempo discreto de $\mathrm{X}_{\text {break }}(T)$ poblacional. Debido a que se supone que la ruptura o quiebre es una descripción adecuada sobre toda la longitud de registros en el intervalo limitado por t1y $\mathrm{t} 3$, sólo un punto de tiempo, a saber: $\mathrm{t} 2 \mathrm{=t}$ (i2), con i2un número entero entre1y $\mathrm{n}$, es considerado como candidato para el corte (t2).

\section{Ajuste polinómico por MCO (mínimos cuadrados ordinarios):}

Se obtiene el polinomio de grado n:

$$
y=a_{0}+a_{1} x+a_{2} x^{2}+\ldots+a_{n} x^{n}(4)
$$

Donde y es la variable dependiente, $\mathrm{x}$ la independiente y los $\mathrm{a}_{\mathrm{i}}$ son los coeficientes a determinar mediante las siguientes ecuaciones normales:

$$
\begin{gathered}
n a_{0}+\left(\sum x_{i}\right) a_{1}+\left(\sum x_{i}^{2}\right) a_{2}+\ldots+\left(\sum x_{i}^{n}\right) a_{n}=\sum y_{i} \\
\left(\sum x_{i}\right) a_{0}+\left(\sum x_{i}^{2}\right) a_{1}+\left(\sum x_{i}^{3}\right) a_{2}+\ldots+\left(\sum x_{i}^{n+1}\right) a_{n}=\sum y_{i} x_{i} \\
\left(\sum x_{i}^{n}\right) a_{0}+\left(\sum x_{i}^{n+1}\right) a_{1}+\left(\sum x_{i}^{n+2}\right) a_{2}+\ldots+\left(\sum x_{i}^{2 n}\right) a_{n}=\sum x_{i}^{n} y_{i}
\end{gathered}
$$

Medias móviles que consisten en una serie de promedios aritméticos (simples o ponderados) calculados a lo largo del tiempo para un período de duración seleccionado L. O sea:

$$
{ }_{L} \bar{Y}_{i}=\frac{1}{L} \sum_{t}^{(L-1)^{\prime} 2} Y_{t=(1-L)^{\prime} 2}
$$

Nótese que lo ideal es que $L$ sea impar para que la media móvil ${ }_{i} \bar{L}_{i}$ este centrada en el período tk donde $k$ es el subíndice correspondiente a la misma. Los datos que se pierden son los (L-1)/2 primeros y los (L-1)/2 últimos de la serie (Montgomery, D,C. and Jhonson, L.A. 1976).

Publicado en formato digital: Dr. Arnobio Germán Pobrete y Dr. Juan Leonidas Minetti. PROPUESTA DE UN INDICE DE SEQUIA PARA VALUAR LA POSIBLE EXPANSION DE LA CELDA DE HADLEY Y SU RELACIÓN CON LA CRISIS HÍDRICA DE LAS REGIONES SUBTROPICALES DEL HEMISFERIO SUR. Revista Geográfica Digital. IGUNNE. Facultad de Humanidades. UNNE. Año 12. № 24. Julio - Diciembre 2015. ISSN 1668-5180 Resistencia, Chaco.

En: http://hum.unne.edu.ar/revistas/geoweb/default.htm 


\section{Índice de sequía del hemisferio sur (ISA)}

En las áreas de CAS del HS se han estimado los índices de sequías mensuales (ISM) y anuales (ISA) propuestos por Minetti (2010). EI ISM fue computado para todos los meses en las localidades secas, por debajo de su valor mediano, respecto del total de las mismas. Este índice oscila entre $0 \mathrm{y}$ 1 con un valor central de 0.5 . EI ISA es la sumatoria de los ISM y oscila entre 0 y 12 con valor central de 6. Mientras que el índice de sequía para el periodo nival (ISQHS-AS) resulta de promediar los índices mensuales comprendidos entre abril-septiembre. Todos han sido consistidos en Sudamérica con información de precipitaciones de una grilla proporcionada por el Reanálysis I (figura 5). Los ISA e ISQHS-AS de el CAS del HS y en particular para cada subregión ( $\mathrm{CH}, \mathrm{AU}$ y SA) han sido analizados en el largo plazo como tendencias ajustadas por polinomios de 5to. Grado con el método de mínimos cuadrados ordinarios (Ecuación 5)y medias móviles (Ecuación 6) (WMO, 1969) recién descriptos.

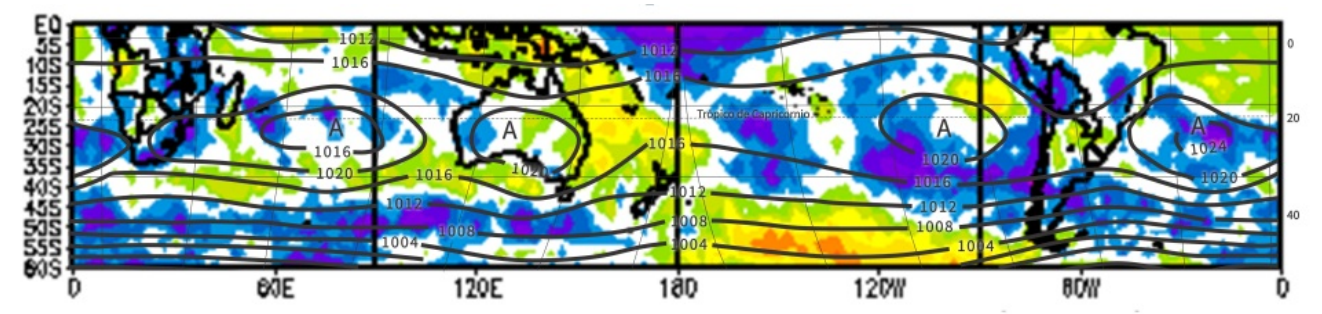

A.pr to Sep: 1979 to 2011: 1000mb CMAP Precipitation (Enhanced) Seasonal Correlation w/Apr to Sep ISQHS2.txt

CMAP Enhanced Precipitotion

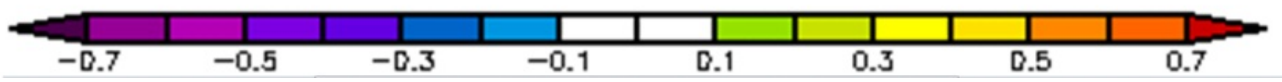

Figura 5: Validación mediante el Reanalysis del índice de sequía del hemisferio Sur para el período abrilseptiembre.

Mediante el Reanalysis I se valida el ISQHS-AS tal cual lo muestra la figura 5, en la que se aprecia que hay una correlación inversa en los tres continentes entre el mismo y el ratio de precipitación en el periodo abril-septiembre del año 1948 hasta 2012, lo que confirma su representatividad.

Para valuar la expansión de la Celda de Hadley se usan los datos de la temperatura global basados en la hipótesis de que ésta, es la que activa a la primera (Broccoli et al., 2006; Haug et al., 1991; Xiao-WeiQuan et al., 2004; Minetti et al. 2010), dado que los autores aun no cuentan con un índice confiable que mida directamente dicha expansión.

\section{RESULTADOS Y DISCUSIÓN}

Haciendo uso de los datos disponibles del ISQHS-AS y la temperatura global (TG), se pretende encontrar el vínculo entre ambos, con el objeto de mostrar si la celda de Hadley $(\mathrm{HC})$ influye sobre la intensidad y expansión de los anticiclones subtropicales del hemisferio sur que inducen a un secamiento en las regiones ubicadas en el CAS. Debido a esto es que se elige el periodo abrilseptiembre, puesto que, en él se produce la precipitación en dichas regiones y almacenamiento de nieve en los Andes Áridos.

Publicado en formato digital: Dr. Arnobio Germán Pobrete y Dr. Juan Leonidas Minetti. PROPUESTA DE UN INDICE DE SEQUIA PARA VALUAR LA POSIBLE EXPANSION DE LA CELDA DE HADLEY Y SU RELACIÓN CON LA CRISIS HÍDRICA DE LAS REGIONES SUBTROPICALES DEL HEMISFERIO SUR. Revista Geográfica Digital. IGUNNE. Facultad de Humanidades. UNNE. Año 12. No 24. Julio - Diciembre 2015. ISSN 1668-5180 Resistencia, Chaco.

En: http://hum.unne.edu.ar/revistas/geoweb/default.htm 


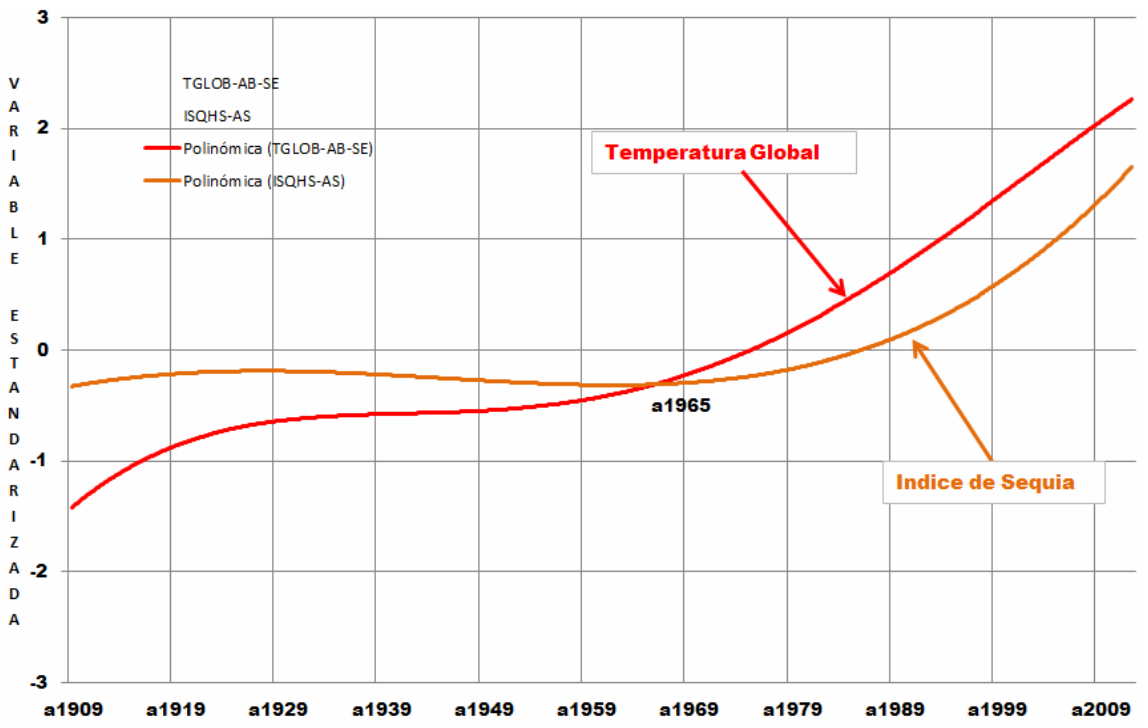

Figura 6:Ajuste polinómico de quinto grado a la temperatura global e índice de sequía hemisférico, ambos para el periodo abril-septiembre.

La figura 6 muestra los ajustes polinómicos realizados a la temperatura global (TG) y el índice de sequía del HS periodo 1909-2012para verificar el comportamiento conjunto de ambos en el largo plazo, siendo su correlación $r=0.43$ significativa al $5 \%$.

Se observa que la TG tiene un continuo ascenso mientras que el ISA comienza con valores moderadamente elevados a principios de siglo, teniendo un descenso suave hasta el año 1965, cuando comienza a aumentar a un ritmo semejante al de la TG.

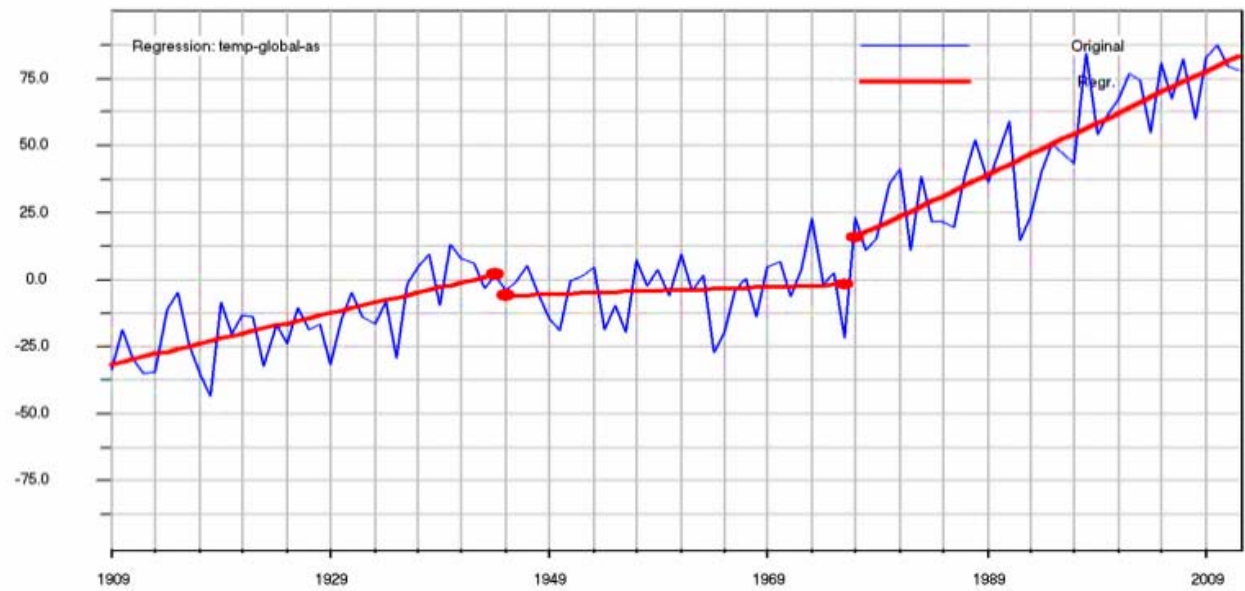

Figura 7: Puntos de ruptura detectados con el procedimiento Break-Regression en la marcha interanual de la temperatura global.

Teniendo en cuenta lo anterior, para encontrar patrones de comportamiento de los índices en análisis se decide aplicar el método BR. Analizando con dicha metodología la temperatura global, en la figura 7 se observan los años en los que se produjeron cambios significativos en su marcha interanual:

Publicado en formato digital: Dr. Arnobio Germán Pobrete y Dr. Juan Leonidas Minetti. PROPUESTA DE UN INDICE DE SEQUIA PARA VALUAR LA POSIBLE EXPANSION DE LA CELDA DE HADLEY Y SU RELACIÓN CON LA CRISIS HÍDRICA DE LAS REGIONES SUBTROPICALES DEL HEMISFERIO SUR. Revista Geográfica Digital. IGUNNE. Facultad de Humanidades. UNNE. Año 12. No 24. Julio - Diciembre 2015. ISSN 1668-5180 Resistencia, Chaco.

En: http://hum.unne.edu.ar/revistas/geoweb/default.htm 
1909-1944, 1945-1976, 1977-2012. Se constata que: en el primero tuvo un crecimiento moderado, en el segundo se estabilizó, mientras que a partir de 1977 registró una fuerte aceleración perdurable hasta 2014, de lo cual se infiere, de acuerdo a la hipótesis planteada, que la actividad y expansión de la celda de Hadley también se incrementaría desde ese año.

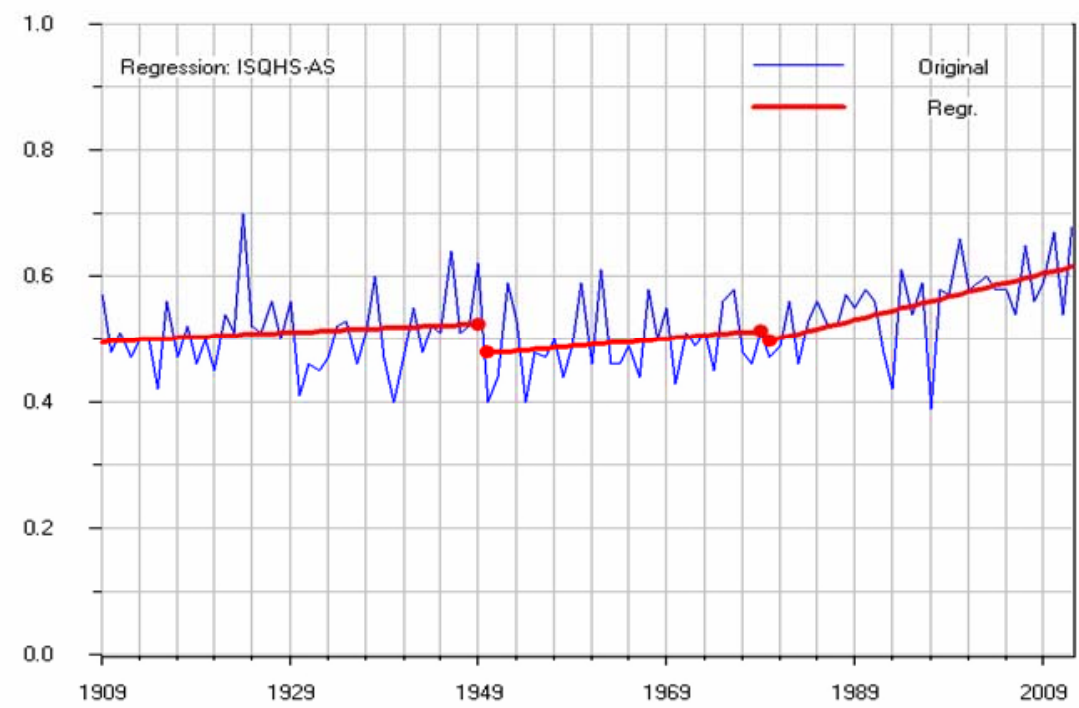

Figura 8: Puntos de ruptura detectados con el procedimiento Break-Regression en la marcha interanual del índice de sequía del hemisferio sur en el periodo abril-septiembre.

Para verificar si en el ISQHS-AS se produjeron cambios semejantes a los de la TG se aplica el test $\mathrm{BR}$, cuyo resultado se muestra en la figura 8 . Los puntos de cambio encontrados que delimitan los intervalos de igual tendencia significativa son: 1909-1949 en el cual el ISQHS-AS presenta un moderado ascenso, 1950-1979con un leve crecimiento, y 1980-2012cuando su tendencia creciente se hace muy significativa.

Comparando los ritmos de crecimiento derivados del comportamiento de la tendencia en ambos, se verifica que salvo desfases no significativos en sus puntos de ruptura, tienen cambios similares en la tendencia, en especial en el segundo y tercer periodo cuando son coherentes. Estos resultados inducen a realizar una correlaccion segmentada entreel ISQHS-AS y la TG teniendose en cuenta los intervalos comunes detectados.

Publicado en formato digital: Dr. Arnobio Germán Pobrete y Dr. Juan Leonidas Minetti. PROPUESTA DE UN INDICE DE SEQUIA PARA VALUAR LA POSIBLE EXPANSION DE LA CELDA DE HADLEY Y SU RELACIÓN CON LA CRISIS HÍDRICA DE LAS REGIONES SUBTROPICALES DEL HEMISFERIO SUR. Revista Geográfica Digital. IGUNNE. Facultad de Humanidades. UNNE. Año 12. № 24. Julio - Diciembre 2015. ISSN 1668-5180 Resistencia, Chaco.

En: http://hum.unne.edu.ar/revistas/geoweb/default.htm 


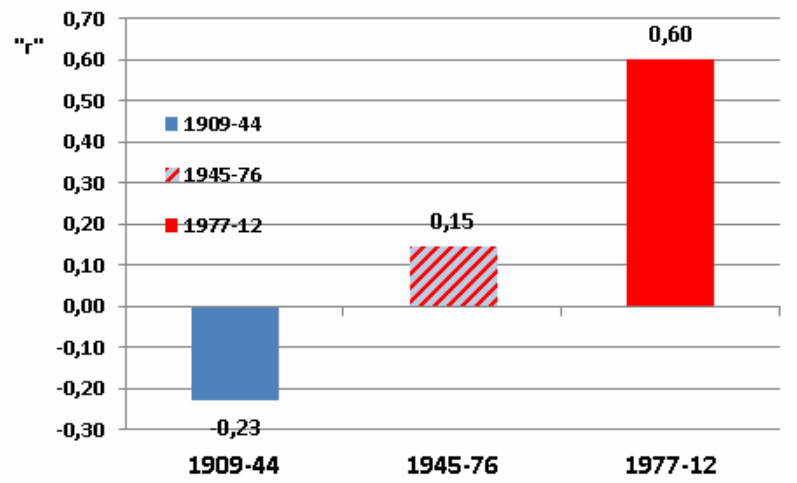

Figura 9: Resultado de la correlación segmentada entre la TG y el ISQHS-AS, teniendo en cuenta los intervalos detectados en la TG Rojo=significativo al 5\%.

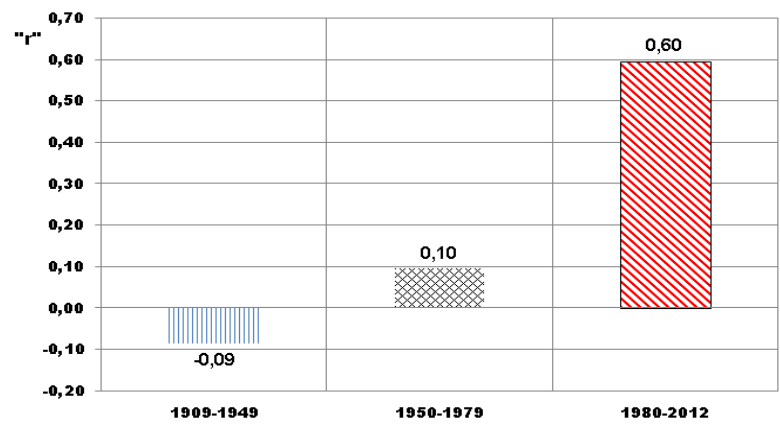

Figura 10: Resultado de la correlación segmentada entre la TG y el ISQHS-AS teniendo en cuenta los intervalos detectados en el ISQHS-AS. Rojo=significativo al $5 \%$.

Los resultados se muestran en la figura 9, donde se observa que la única correlación significativa es la que corresponde al periodo 1977-2012, de lo que se infiere que la sequía hemisférica creció a un ritmo semejante al de la TG, que induciría a pensar que la celda de Hadley se aceleró expandiendo los desiertos subtropicales.

De acuerdo a los puntos de ruptura encontrados en ISQHS-AS en la figura 10 se muestran las correlaciones en los intervalos detectados siendo significativa solamente en el periodo 1980-2012. Por lo que también resultaría apropiado decir que el marcado crecimiento de la TG aceleró la expansión/activación de la HC y de esa manera se acentuó la sequía en el hemisferio sur por las razones ya apuntadas.

Publicado en formato digital: Dr. Arnobio Germán Pobrete y Dr. Juan Leonidas Minetti. PROPUESTA DE UN INDICE DE SEQUIA PARA VALUAR LA POSIBLE EXPANSION DE LA CELDA DE HADLEY Y SU RELACIÓN CON LA CRISIS HÍDRICA DE LAS REGIONES SUBTROPICALES DEL HEMISFERIO SUR. Revista Geográfica Digital. IGUNNE. Facultad de Humanidades. UNNE. Año 12. No 24. Julio - Diciembre 2015. ISSN 1668-5180 Resistencia, Chaco.

En: http://hum.unne.edu.ar/revistas/geoweb/default.htm 

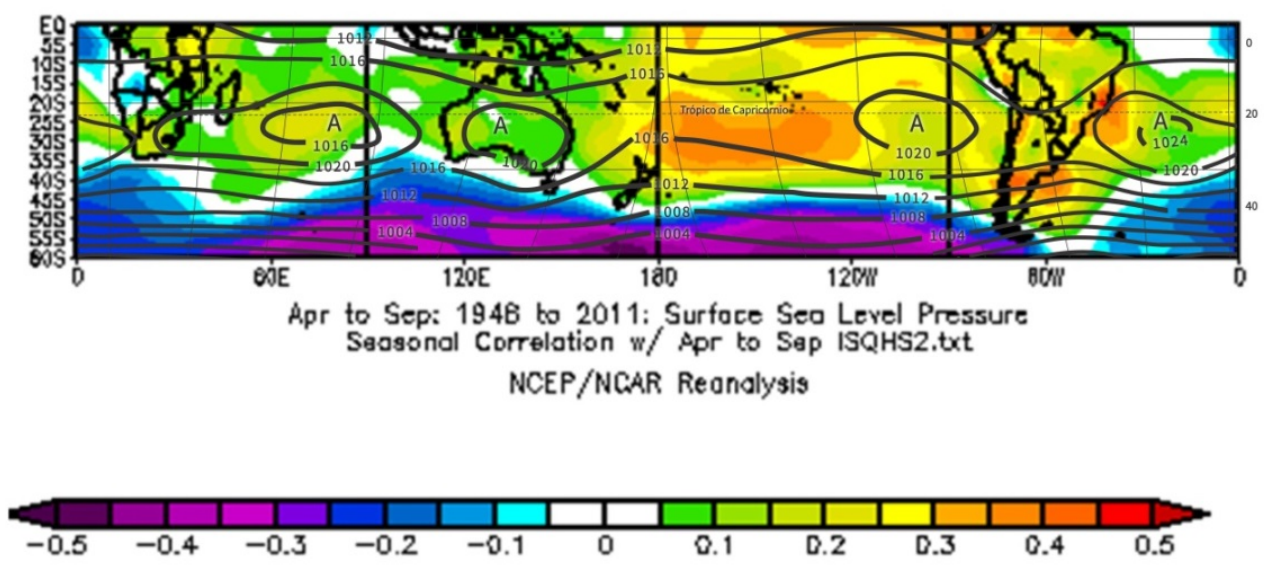

Figura 11:Correlación entre el ISA y la presión al nivel del mar efectuada con el Reanalysis I.Periodo AbrilSeptiembre (1948-2011)

Haciendo uso del Reanalysis I, se realiza la verificación areal de la correlación directa significativa encontrada para el periodo 1948-2011, entre el índice el ISQHS-AS y la presión atmosférica al nivel del mar. La figura 11, muestra que la asociación entre los mismos es significativa en una banda que aproximadamente sigue la latitud donde se encuentra el cinturón de alta presión del HS. Siendo muy significativa en el área que ocupa el Anticiclón del Pacifico Sur (ASPSO). Hecho que es coherente con la presurización y expansión de los mismos induciendo la falta de precipitación.
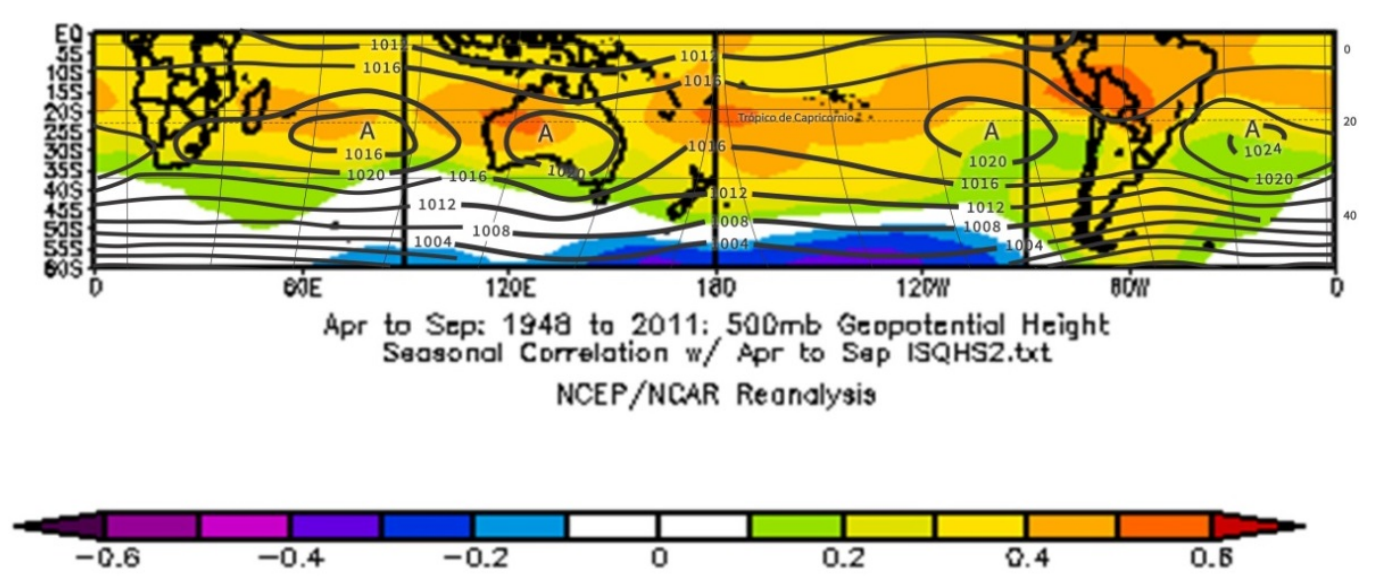

Figura 12: Correlación entre el ISQHS-AS y el geopotencial de los $500 \mathrm{mb}$ con el Reanalysis I.Periodo AbrilSeptiembre (1948-2011)

Para confirmar lo anterior se analiza la asociación entre el ISQHS-AS y el geopotencial de los $500 \mathrm{mb}$, que se muestra en la figura 12. Se observa que hay un aumento de las correlaciones directas significativas entre ambos, especialmente en el desierto australiano, la costa adyacente al Kalahari, Madagascar, Puna boliviana y en menor medida en la Patagonia. Sin embargo, la asociación es menos significativa en Chile Central.

Publicado en formato digital: Dr. Arnobio Germán Pobrete y Dr. Juan Leonidas Minetti. PROPUESTA DE UN INDICE DE SEQUIA PARA VALUAR LA POSIBLE EXPANSION DE LA CELDA DE HADLEY Y SU RELACIÓN CON LA CRISIS HÍDRICA DE LAS REGIONES SUBTROPICALES DEL HEMISFERIO SUR. Revista Geográfica Digital. IGUNNE. Facultad de Humanidades. UNNE. Año 12. No 24. Julio - Diciembre 2015. ISSN 1668-5180 Resistencia, Chaco.

En: http://hum.unne.edu.ar/revistas/geoweb/default.htm 


\section{Análisis areal de la correlación segmentada}

Se decide verificar la influencia de la TG mostrada en el análisis anterior y por ende la posible expansión/activación de la $\mathrm{HC}$, sobre el comportamiento de las distintas variables que tienen que ver con la precipitación en las regiones afectadas por el cinturón subtropical de altas presiones, para lo cual se estima arealmente la correlación segmentada mostrada en las figuras 9 y 10.

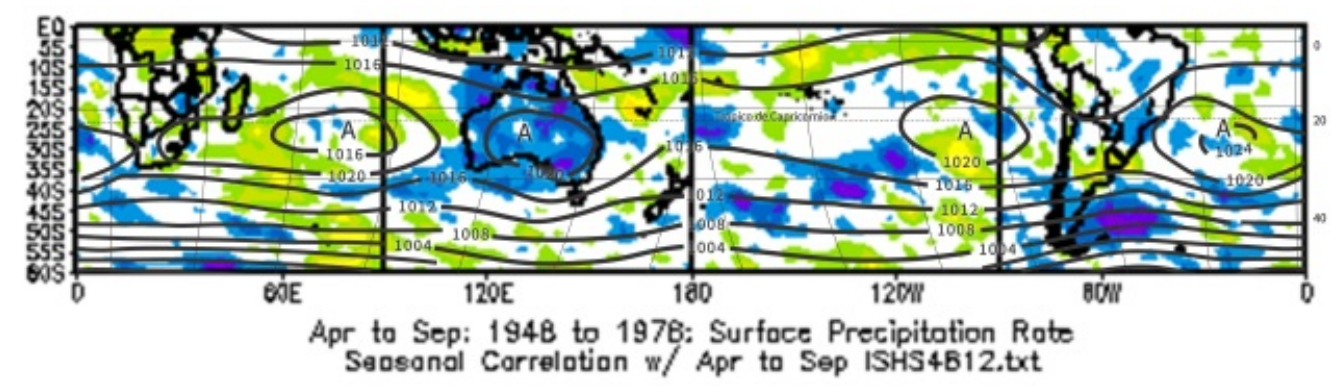

NCEP/NCAR Reonalysis

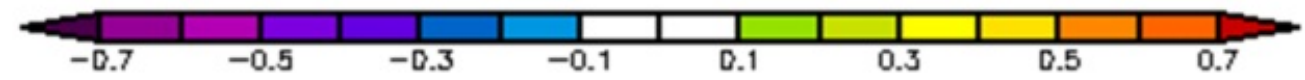

Figura 14: Correlación entre el ISQHS-AS y el ratio de precipitación en Abril-Septiembre según el NCEP/NCAR para el periodo 1948-1978 con el Reanalysis I.
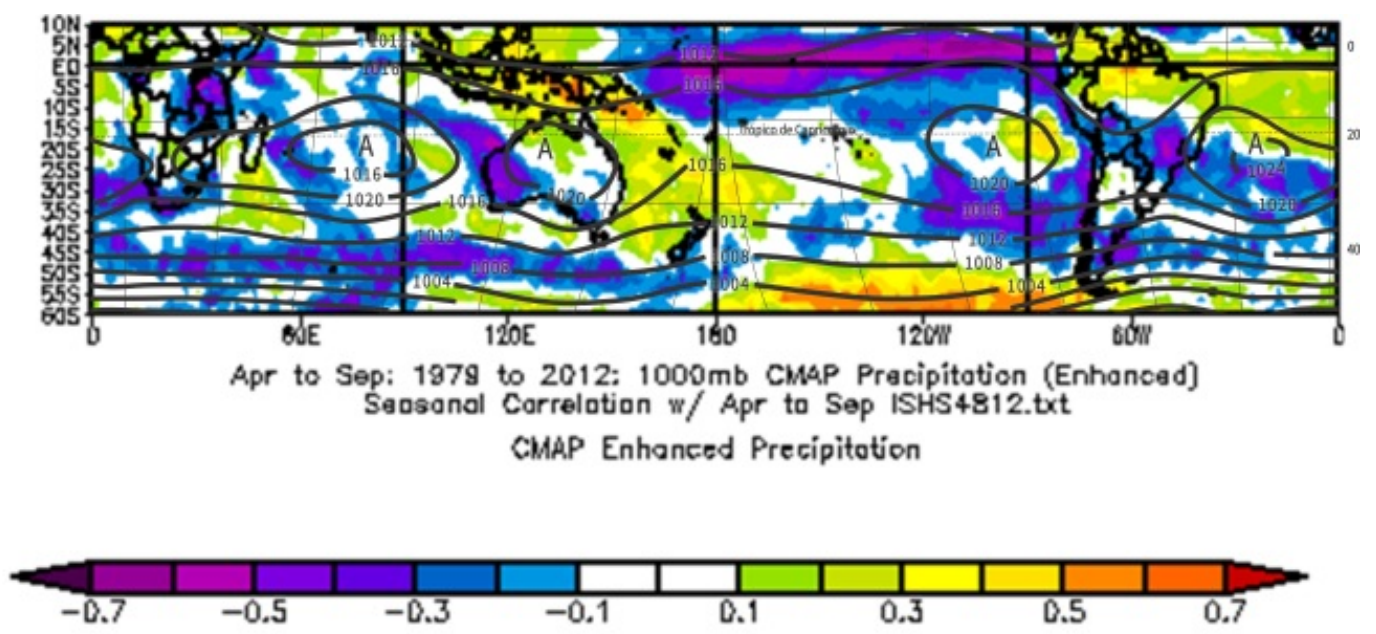

Figura 15: Correlación entre el ISQHS-AS y el ratio de precipitación en Abril-Septiembre según el CMAP para el periodo 1979-2012 con el Reanalysis I.

En la figura 14 se muestra la correlación entre las precipitaciones con el ISQHS-AS para el periodo 1948-1978 y en la figura 15 para 1979-2012. Se observa que en el primer caso hay correlaciones inversas confinadas en el continente australiano y en menor medida en la Patagonia sur solamente. Sin embargo, en el segundo periodo esta correlación inversa se extiende en toda la franja anticiclónica con énfasis en el Kalahari, oeste de Australia y anticiclón del Pacifico sur con Chile

Publicado en formato digital: Dr. Arnobio Germán Pobrete y Dr. Juan Leonidas Minetti. PROPUESTA DE UN INDICE DE SEQUIA PARA VALUAR LA POSIBLE EXPANSION DE LA CELDA DE HADLEY Y SU RELACIÓN CON LA CRISIS HÍDRICA DE LAS REGIONES SUBTROPICALES DEL HEMISFERIO SUR. Revista Geográfica Digital. IGUNNE. Facultad de Humanidades. UNNE. Año 12. No 24. Julio - Diciembre 2015. ISSN 1668-5180 Resistencia, Chaco.

En: http://hum.unne.edu.ar/revistas/geoweb/default.htm 
Central incluido. Lo que demostraría que la aceleración de la HC habría repercutido en la expansión espacial de la asociación inversa, entre el índice de sequía y el monto de las precipitaciones.
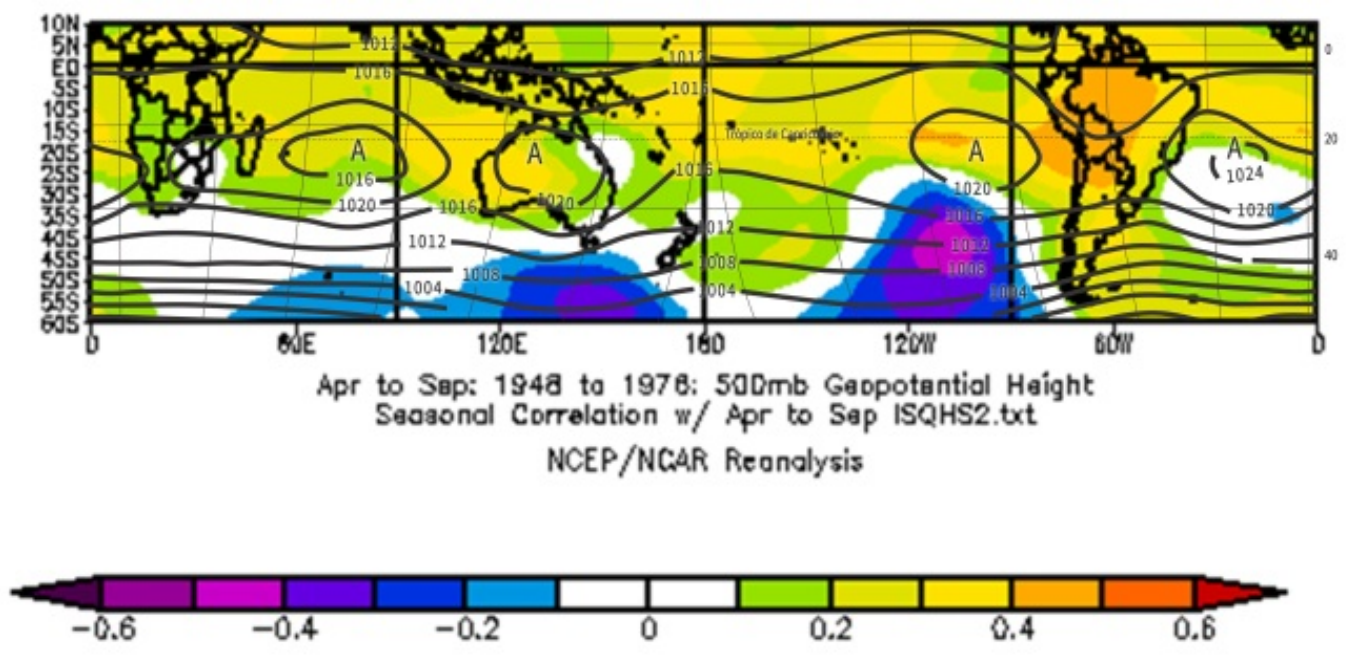

Figura 16: Correlación entre el ISQHS-AS y geopotencial de los 500 mb en Abril-Septiembre según el Reanalysis I del NCEP/NCAR para el periodo 1948-1976.
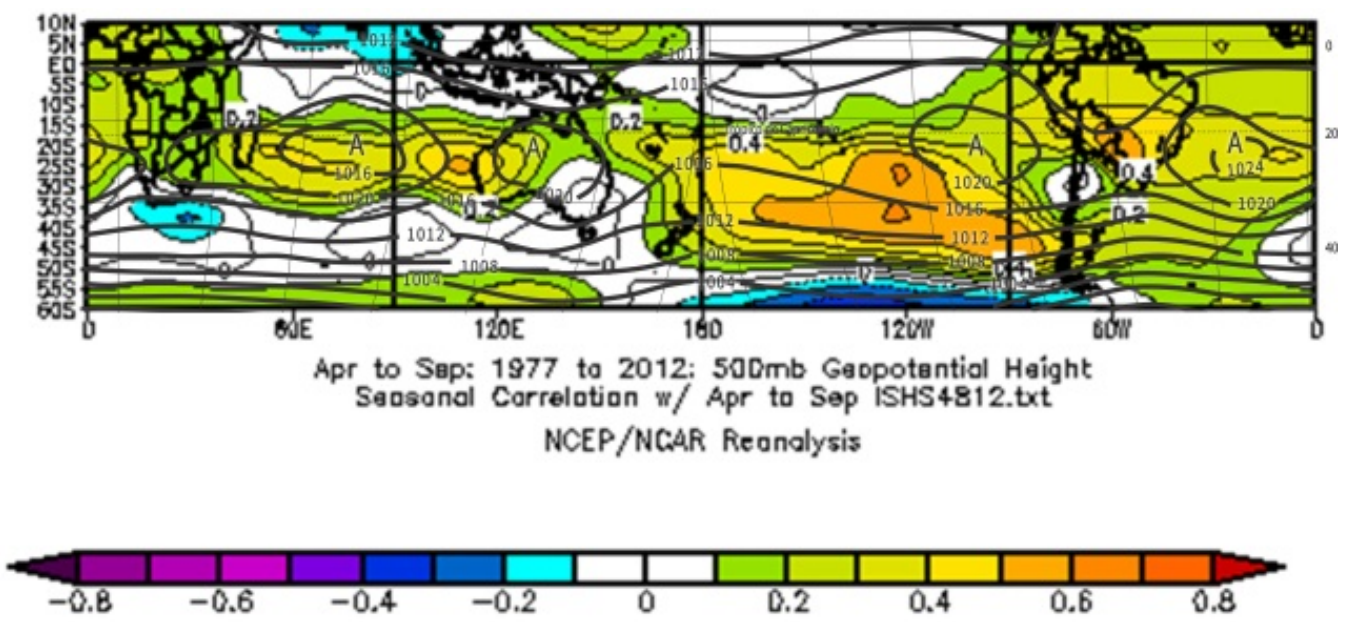

Figura 17: Correlación entre el ISQHS-AS y geopotencial de los 500 mb en Abril-Septiembre según el Reanalysis I del NCEP/NCAR para el periodo 1977-2012.

Para encontrar una explicación dinámica de lo anterior se calcula la distribucion espacial de la correlacion entre el ISQHS-AS y el geopotencial de los $500 \mathrm{mb}$ (G500mb) en los periodos citados(figuras 16 y 17). Se observa que en 1948-1976 las correlaciones son positivas en el mar adyacente al Kalahari, el oeste de Australia con baja significacion, y en la Puna (más relevante). Se destaca en un área ubicada al sur del anticiclon del Pacifico Sur una correlacion inversa que induciría a pensar que a menor G500mb,mayor índice de sequia por lo tanto menor precipitación, por lo cual en dicha área habría una contradicción difícil de dilucidar.

Publicado en formato digital: Dr. Arnobio Germán Pobrete y Dr. Juan Leonidas Minetti. PROPUESTA DE UN INDICE DE SEQUIA PARA VALUAR LA POSIBLE EXPANSION DE LA CELDA DE HADLEY Y SU RELACIÓN CON LA CRISIS HÍDRICA DE LAS REGIONES SUBTROPICALES DEL HEMISFERIO SUR. Revista Geográfica Digital. IGUNNE. Facultad de Humanidades. UNNE. Año 12. No 24. Julio - Diciembre 2015. ISSN 1668-5180 Resistencia, Chaco.

En: http://hum.unne.edu.ar/revistas/geoweb/default.htm 
Sin embargo, en el periodo 1977 - 2012 se observan correlaciones relevantes en todo el cinturón de los anticiclones subtropicales siendo muy significativa en la región que abarca el ASPSO, salvo en el norte de Chile donde no existe correlacion. Esto llevaría a pensar que el geopotencial de $500 \mathrm{mb}$ se intensificó en dicho cinturón a partir de 1977 coincidiendo con la acelaracion de la TG, lo que repercutiría en el aumento dela sequía hemisferica estimada por el ISQHS-AS.De esta manera se verificaría una conexión entre la actividad de la HC y la potenciación de la presión en altura, hecho que repercutiría en la disminución de la precipitación en el periodo abril-septiembre en el lapso 19772012, mostrado en la figura 15.
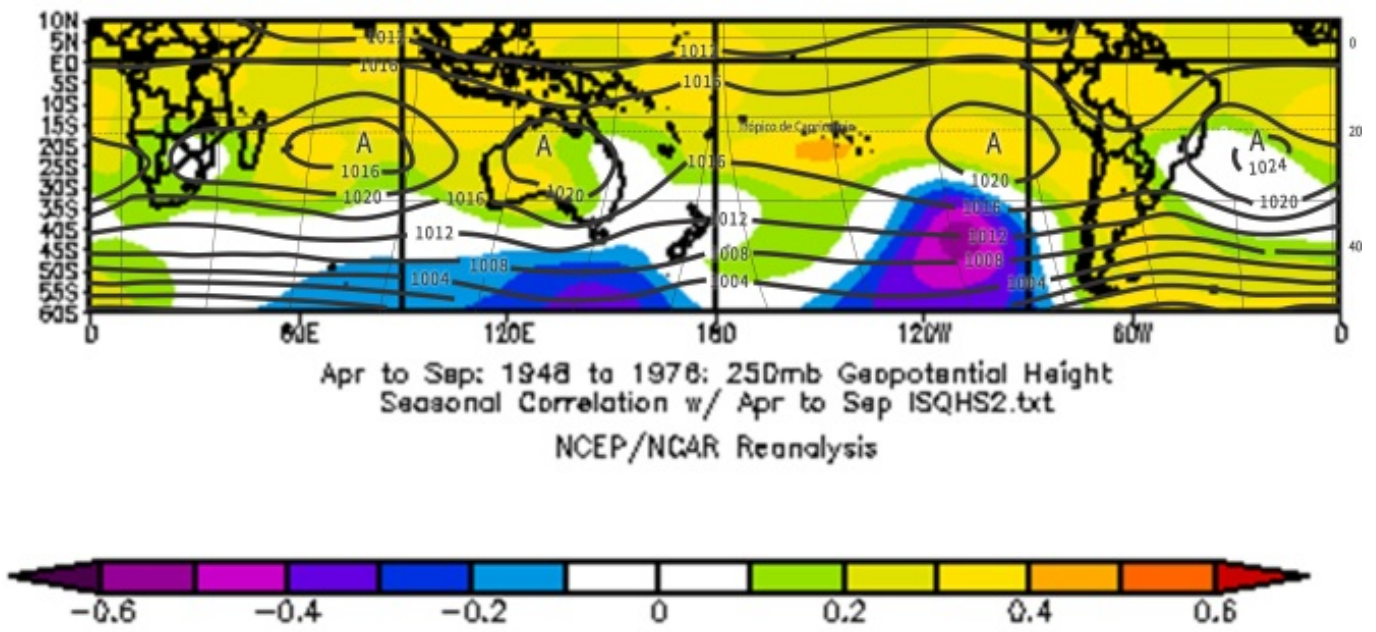

Figura 18: Correlación entre el ISQHS-AS y geopotencial de los $250 \mathrm{mb}$ en Abril-Septiembre según el Reanalysis I del NCEP/NCAR para el periodo 1948-1976.
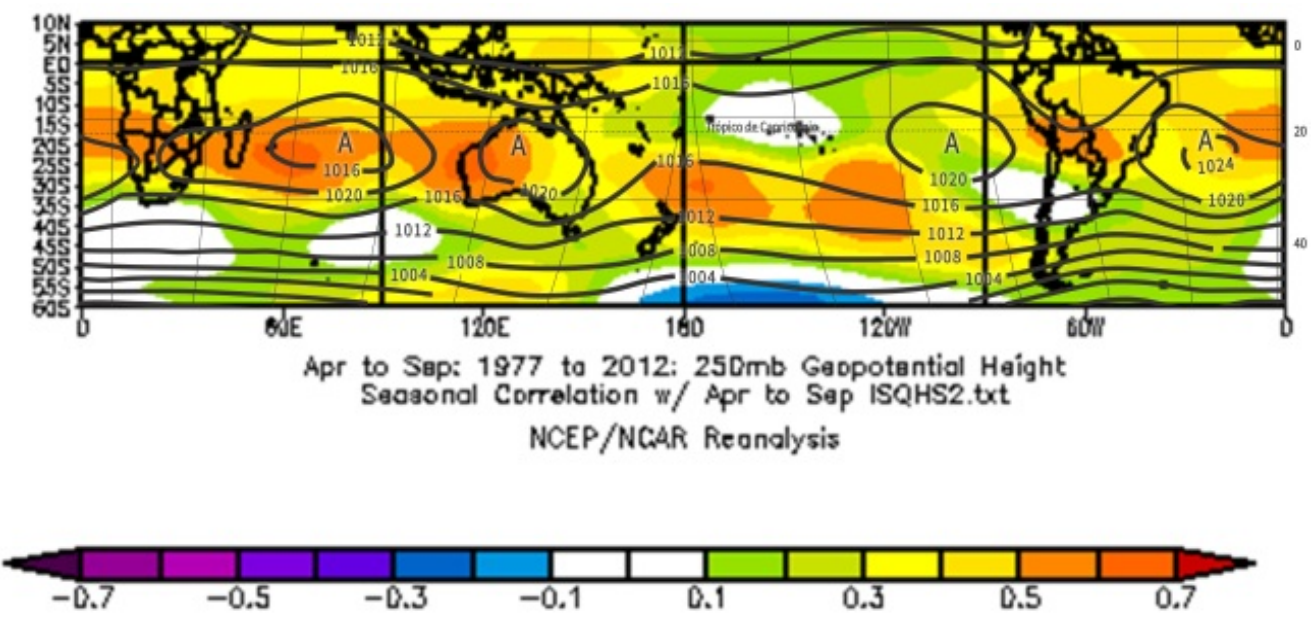

Figura 19: Correlación entre el ISQHS-AS y geopotencial de los 250mb en Abril-Septiembre según el Reanalysis I del NCEP/NCAR para el periodo 1977-2012.

Para confirmar lo encontrado en el nivel G500mb se realiza el mismo análisis para el de los $250 \mathrm{mb}$ (G250mb). Las figuras 18 y 19 muestran los resultados para los periodos 1948-1976 y 1977-2012 respectivamente. Se observa que hay una marcada diferencia de correlaciones entre ambos, puesto que en el primero son positivas pero no significativas, y además se presenta el mismo vórtice

Publicado en formato digital: Dr. Arnobio Germán Pobrete y Dr. Juan Leonidas Minetti. PROPUESTA DE UN INDICE DE SEQUIA PARA VALUAR LA POSIBLE EXPANSION DE LA CELDA DE HADLEY Y SU RELACIÓN CON LA CRISIS HÍDRICA DE LAS REGIONES SUBTROPICALES DEL HEMISFERIO SUR. Revista Geográfica Digital. IGUNNE. Facultad de Humanidades. UNNE. Año 12. No 24. Julio - Diciembre 2015. ISSN 1668-5180 Resistencia, Chaco.

En: http://hum.unne.edu.ar/revistas/geoweb/default.htm 
encontrado en el G500mb con correlación inversa en el océano Pacífico Sur en las proximidades del meridiano de $120^{\circ} \mathrm{W}$. Lo que implicaría que en esa región hayan mayores precipitaciones, poniéndose de manifiesto la posible escasa repercusión de la activación de la HC en la misma.

Sin embargo en el periodo 1977-2012 se observan correlaciones positivas y significativas en toda la banda de los anticiclones subtropicales, corroborando lo encontrado en el nivel G500mb, es decir, que la activación de la $\mathrm{HC}$ producida por una TG en rápido aumento, inhibe el paso de los agentes precipitantes en altura, dando lugar a que se produzcan escasas precipitaciones. Por otra parte, el área encontrada con correlaciones inversas en el primer periodo no se manifiesta, corroborando la sustancial diferencia entre uno y otro.

\section{CONCLUSIONES}

El Índice de sequía del Hemisferio Sur fue verificado por medio del Reanalysis I, por lo que resultó valido en el periodo abril-septiembre (ISQHS-AS) para lograr las siguientes conclusiones:

Tiene una correlación positiva con la temperatura global(TG), la presión al nivel del mar y el geopotencial de los $500 \mathrm{mb}$, en el periodo $1909-2012$ en todo el cinturón de los anticiclones subtropicales. Hecho que valida la hipótesis: que una mayor subsidencia producida por la expansión/activación de la celda de Haldey, induciría una potenciación y expansión de los anticiclones subtropicales.

De la segmentación obtenida con el método Break Regression, se verifica que la única correlación significativa entre el ISQHS-AS y la temperatura global, es la que corresponde al periodo 1977-2012. Esto equivaldría decir que la sequía hemisférica creció a un ritmo semejante al de la TG desde ese año, lo que induciría a pensar que la celda de Hadley se aceleró expandiendo los desiertos subtropicales.

Con la aplicación del Reanalysis I, se verifica que hay marcadas diferencias areales de la correlación entre los periodos anterior y posterior a 1977, cuando comienza la aceleración de la temperatura global(TG). Notándose un incremento significativo de la asociación directa entre el ISQHS-AS con la presión a nivel del mar, los $500 \mathrm{mb}$ y $250 \mathrm{mb}$, e inversa con el monto de las precipitaciones; esto explicaría que, debido a la aceleración de la TG y por ende una mayor actividad de la celda de Haldey $(\mathrm{HC})$, activarían los mecanismos subsidentes en las regiones subtropicales potenciando y secando los anticiclones, los que a su vez inhibirían los mecanismos precipitantes dando lugar a una disminución de las precipitaciones. De esta manera se entiende porque el calentamiento global valiéndose de la $\mathrm{HC}$, influye negativamente en la caída nival en los Andes Áridos y precipitaciones invernales en la banda subtropical de Sudáfrica y Australia.

\section{AGRADECIMIENTOS}

Se agradece a la Universidad Nacional de San Juan y la ANCYT, PICTO- UNSJ-2009-0150-BID, por sus aportes económicos en el desarrollo de este trabajo y "Análisis climatológico-dinámico de la crisis hídrica de los últimos años en cuyo y chile central en el contexto del cambio climático global". Cod.F994/FFHA, Res.:18/14-CS-UNSJ. CICITCA-UNSJ.

\footnotetext{
Publicado en formato digital: Dr. Arnobio Germán Pobrete y Dr. Juan Leonidas Minetti. PROPUESTA DE UN INDICE DE SEQUIA PARA VALUAR LA POSIBLE EXPANSION DE LA CELDA DE HADLEY Y SU RELACIÓN CON LA CRISIS HÍDRICA DE LAS REGIONES SUBTROPICALES DEL HEMISFERIO SUR. Revista Geográfica Digital. IGUNNE. Facultad de Humanidades. UNNE. Año 12. No 24. Julio - Diciembre 2015. ISSN 1668-5180 Resistencia, Chaco.
}

En: http://hum.unne.edu.ar/revistas/geoweb/default.htm 


\section{BIBLIOGRAFÍA}

Broccoli, A.J., K.A. Dahl and R.J. Stouffer, 2006: Response of the ITCZ to Northern cooling. Geo. Res. Let. 33, doi: 10.1029/2005GL024546.

Cai, W., Cowan, T. y Thatcher,M.,2012. Rainfall reductions over Southern Hemisphere semi-arid regions: the role of subtropical dry zone expansion. Rev. Scientific Reports.CSIRO Marine and Atmospheric Research, Aspendale, Victoria, Australia.

Diaz, H.F., y B. Bradley, 2004. The Hadley Circulation: Present, Past and Future, Kluwer Academic Publishers, The Netherlands, 220.

Draper N. R., Smith, H., 1998. Applied Regression Analysis.En:.Wiley (ed.). 3rd Edition ISBN: 9780-471-17082-2., 736. New York.

Haug, G.H., K.A. Hughen, D.M. Sigman, L.C. Peterson and U. Röhl, 2001: Southward Migration of the Intertropical Convergence Zone Through the Holocene. The Geographical Journal, vol. 157, No2, 1304-1308.

Hu Y. y Q. Fu, 2007.Observed poleward expansion of the Hadley circulation since 1979. Atm. Chem. Phys., 7, 5229-5236.

Kistler, R., Kalnay, E., Collins, W., Saha, S., White, G., Woollen, J., Chellian, M., Ebisuzaki, W., Kanamitso, M., Kousky, V., Lu, J., Vecchi G.A. y Reichler T., 2007.Expansion of the Hadley cell under global warming. Geo. Res. Lett. 34, L06805, doi 10.1029/2006GL028443.

Lu, J., Deser, C.\&R., T. Cause of the widening of the tropical belt since 1958. Geophys. Res. Minetti, J.L., Poblete, A.G., W.M. Vargas, Ovejero D.P., 2010.El Calentamiento Global Y La Circulación De Hadley En El Hemisferio Sur. Revista Brasilera de Meteorología.

Minetti, J.L., Vargas, W.M., Poblete, A.G. y Mendoza, E.A., 2009.Latitudinal positioning of the subtropical anticyclone along the Chilean coast.Aus. Met. and Oce. Jou. 58, 107-117. Australia.

Minetti, J.L., W.M. Vargas, A.G. Poblete and E.A. Mendoza, 2009: Latitudinal positioning of the subtropical anticyclone along the Chilean coast. Aus. Met. and Oce. Jou. 58, 107-117. Australia.

Mudelsee, M., 2009.Break Funtion Regression, A Tool for Quantifying Trend Change In Climate Time Series. The European Physical Journal Special Topic. New York.

Poblete A.G., Minetti, J. L. 2015. El Calentamiento Global Y Su Posible Influencia En La Disminución De Las Precipitaciones En Las Regiones Subtropicales Del Hemisferio Sur. Enviado a Meridiano - Revista de Geografía, número 1, 2012 - versión digital. http://www.revistameridiano.org/

Poblete, A. G., Valdez, V. 2014.Posible Impacto de la Activación de la Celda de Hadley en la Intensidad y Corrimiento del Anticiclón del Pacifico Sur. IX Jornadas Patagónicas de Geografía. Universidad Nacional de la Patagonia Austral. Argentina. (12 - 15 de Marzo).

Publicado en formato digital: Dr. Arnobio Germán Pobrete y Dr. Juan Leonidas Minetti. PROPUESTA DE UN INDICE DE SEQUIA PARA VALUAR LA POSIBLE EXPANSION DE LA CELDA DE HADLEY Y SU RELACIÓN CON LA CRISIS HÍDRICA DE LAS REGIONES SUBTROPICALES DEL HEMISFERIO SUR. Revista Geográfica Digital. IGUNNE. Facultad de Humanidades. UNNE. Año 12. No 24. Julio - Diciembre 2015. ISSN 1668-5180 Resistencia, Chaco.

En: http://hum.unne.edu.ar/revistas/geoweb/default.htm 
Poblete, A.G., Minetti, J. L. 2013. Variabilidad del Clima Asociado con la Precipitación y Caudales de ríos en Los Andes Áridos-Sudamérica- .Rev. de Geografia UNSJ- ISSN 1514-1942Vol. XVII- N¹7. San Juan. Argentina.

Poblete, A.G., Minetti J. L., Iranzo. D.A., 2013. Cambios de Baja Frecuencia en Ios Principales Factores que Condicionan la Caída de Nieve en Los Andes Centrales. II Congreso Internacional de Hidroclimatología. Facultad de Ciencias Agrarias - Universidad Nacional de Jujuy. Argentina. (11 14 de Septiembre).

Radicella, S.M, Minetti, J.L., Saavedra, N. y Valdivia, J., 1989.Estudio hidroclimatológico de zonas áridas y semiáridas de Latinoamérica. Rev. Geofísica № 30, 19-30. IPGH-OEA. México.

Rusticucci, M. and O.Penalba, 2000.Interdecadal changes in the precipitation seasonal cycle over Southern South America and their relationship with surface temperature. Climate Research $16,1-15$.

Smagorinsky J, 1963. General circulation experiment with primitive equation. Mon. Wea. Rev. 91, $99-164$

Spencer, R.W., Braswell, W. D., Christy, J. R., and Hnilo, J., 2007.Cloud and radiation budget changes associated with tropical intraseasonal oscillations, Geophys. Res. Lett., 34, L15707, doi:10.1029/2007GL029698.

Trenberth y Hurrell, 1994.Variaciones decenales atmósfera y el océano en el Pacífico. Dinámica del Clima, Vol. 9, p 303-319.

Ummenhofer, C.C., M.C. England, G.A. Meyers, M.J. Pook, J.S. Risbey, A.S. Gupta, y A.S. Taschetto, 2009: Wath causes southeast Australia's worst droughts? Geo .Res. Letters, vol. 36, L04706.Doi: 10.1029/2008GL036801.

Viale, M., 2010.Características de las Precipitaciones Orográficas de Invierno sobre los Andes Subtropicales Centrales, Universidad de Bs. As. Facultad de Ciencias Exactas y Naturales Dpto. de Ciencias de la Atmósfera y los Océanos, Tesis presentada para optar por el título de Doctor de la Universidad de Buenos Aires en al área Ciencias de la Atmósfera y los Océanos.

Xiao-Wei Quan, H.F. Diaz y M.P. Hoerling, 2004: Change of the Tropical Hadley Cell Since 1950.Adv.Glo.Chan.Res. Vol. 21, Springer.

Publicado en formato digital: Dr. Arnobio Germán Pobrete y Dr. Juan Leonidas Minetti. PROPUESTA DE UN INDICE DE SEQUIA PARA VALUAR LA POSIBLE EXPANSION DE LA CELDA DE HADLEY Y SU RELACIÓN CON LA CRISIS HÍDRICA DE LAS REGIONES SUBTROPICALES DEL HEMISFERIO SUR. Revista Geográfica Digital. IGUNNE. Facultad de Humanidades. UNNE. Año 12. No 24. Julio - Diciembre 2015. ISSN 1668-5180 Resistencia, Chaco.

En: http://hum.unne.edu.ar/revistas/geoweb/default.htm 